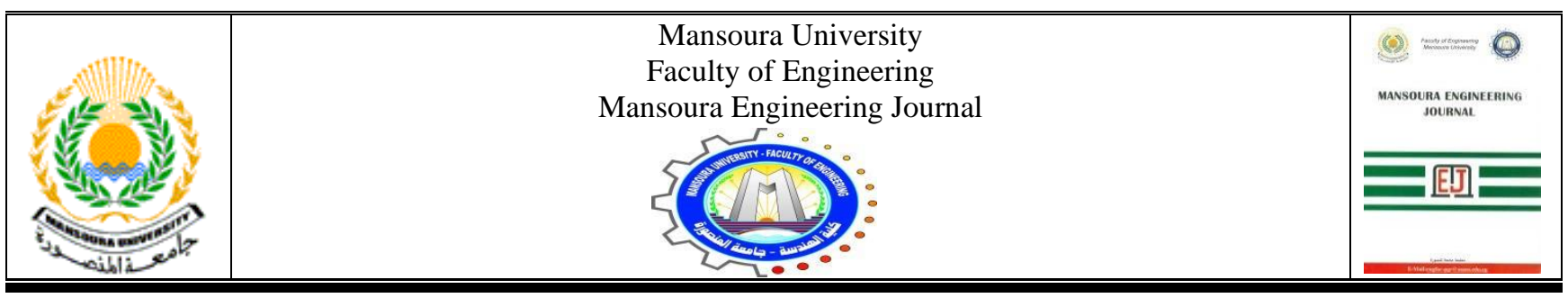

\title{
The Architectural and Urban Formation of the New Cities Identity (Case Study: The New Administrative Capital)
}

\author{
Maryam Ali EL-Baz, Ahmed Al-Tantawy Al-Maadawy and Asmaa Nasr El-din Elbadrawey
}

\begin{abstract}
KEYWORDS: Architectural formation, urban formation, societal identity, architectural and urban identity of the city, indicators
\end{abstract}

\begin{abstract}
The architectural and urban formation of the identity of cities is one of the basic requirements necessary as a result of new urban communities (new cities), in order to meet the requirements of the population to meet the basic needs and document the vocabulary of special architecture

And urbanization is a historical reference for future generations and it was necessary to document the events and periods of time that pass the city to create new national administrative cities and capitals for the old countries, and this was from the period of the new cities in Egypt from 1977 to the present, and seeks to present the concept of urban and architectural identity and its role in determining the shape of new cities and capitals, as well as explain the function of identity and how to preserve it, and the factors affecting it both now and the future, and the presentation of some examples, and the presentation of some examples For contemporary models of contemporary applications of the concept of air, resulting in the development of several indicators through which the new capitals can be evaluated and applied to (the new administrative capital) and come up with clear results.
\end{abstract}

$$
\begin{aligned}
& \text { تعمل كمر آة للمجتمع وللزائر بثقافة معمارية و عمر انية مدفونة وظهرت للمستقبل } \\
& \text { بفكر جديد. } \\
& \text { لللك يسعي البحث لصياغة عناصر تشكيل الهوية المعمارية والعمر انية في } \\
& \text { المدن، وكيفية وجودها كقاعدة اساسية للعو اصم الجديدة وبالأخص (العاصمة ادارية } \\
& \text { جديدة) من خلال: } \\
& \text { 1- التعرف على مفهوم الهوية العمر انية و المعمارية ودور ها في تحديد شكل المدن } \\
& \text { و العو اصم الجديدة وشرح وظيفة الهوية وكيفية الحفاظ عليها. }
\end{aligned}
$$

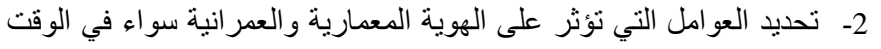

$$
\begin{aligned}
& \text { الحالي او المستقبلي ومعرفة مقومات الهو الهوية. }
\end{aligned}
$$

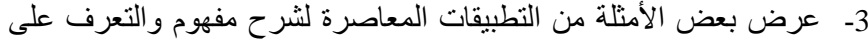

$$
\begin{aligned}
& \text { المتغير ات الحالية و المستقبلية لمكونات الهوية المعمارية و العمر انية. }
\end{aligned}
$$

Ahmed Al-Tantawi Al-Maadawi: Assistant Professor of Architecture, Faculty of Engineering. In 2018, he received a Ph.D. in Architecture from Mansoura University. In 2012, Master of Arc. From Mansoura University. In 2007, B.A. Architecture in 2001. (E-mail: EItantawy_a@mans.edu.eg)

Asmaa Nasr el Din: Lecturer of Arch. Department of Architectural Engineering, Faculty of Engineering, Mansoura University, Ph.D. in Architecture from MSc. In 2011, he holds a Master of Engineering Sciences. From MSc in 2004. Bachelor of Architecture 1998 (E-mail: asmaaelbadrawy@gmail.com)).

\section{I}

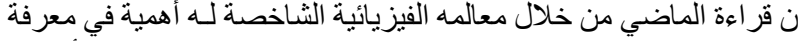

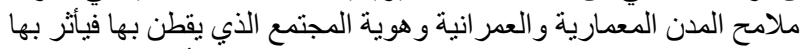

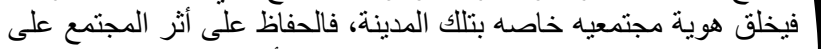

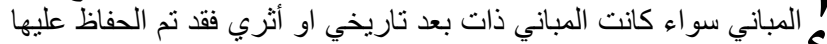

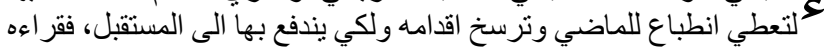

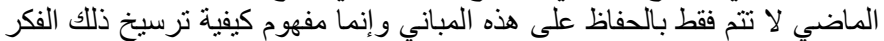

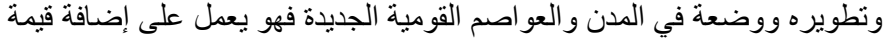

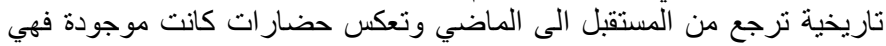

Received: (13 July, 2020) - Revised: (22 September, 2020) - Accepted: (16 October, 2020)

Corresponding Author: Maryam Ali Mohamed EL-Baz: Teaching Assistant at Misr Higher Institute of Engineering \& Technology, Pre-Masters from Mansoura University 2016. Scholarship from several German Univ. in 2016, Pre-Masters from Mansoura Univ. in 2017-2018, BSc. Of Architectural Engineering, Misr Higher Institute of Engineering \&Technology 2016. (Email:maryamelbaz_m30@yahoo.com). 


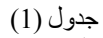

$$
\text { تعاريف الهوية في عمارة و العمران }
$$

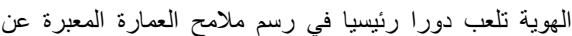

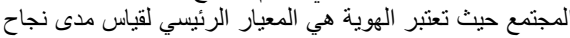

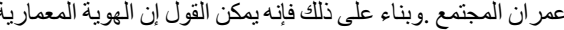

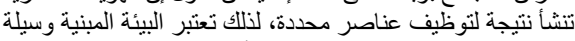

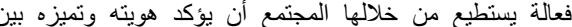

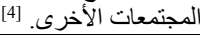

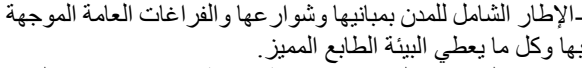

ـالهوية العمرانبة|6|

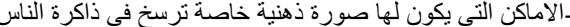

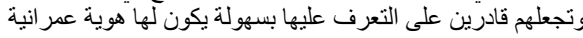

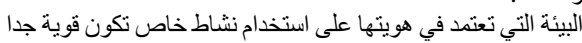

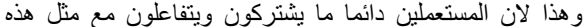

الانشطة المتميزة.

الخطوط الافقية في الجدول بتحدد تعاريف الهوية المعمارية والعمرانية حيث شملت على معظم التعاريف الوضحة فهي بمثابة توضيح للمفردات المستخدمة في البحث.

ثانيا مفهوم الهوية في العمارة و العدران حيث يمكن توضــيح كلا منهما من

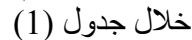

ثالثا مفهوم التشكبل: هو علم وفن صياغة العناصر المكونة للعمر ان مثل العناصر

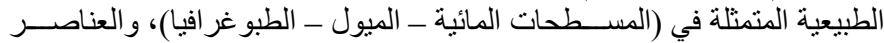

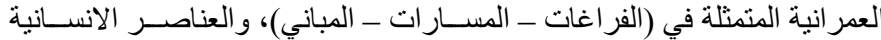

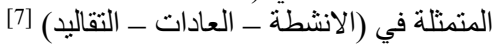

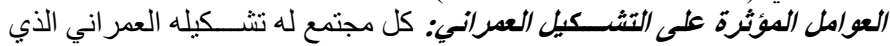

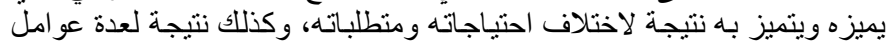

تاعفاعل مع بعضها.

ــالعو امل الطبيعية (العو امل الجغر افية كطبو غر افيا الموقعــ العو امل المناخية)

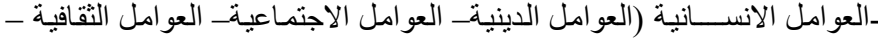

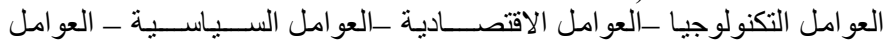

[8] التشريعية التوبلة

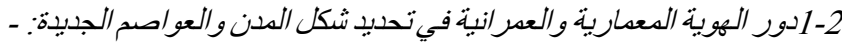

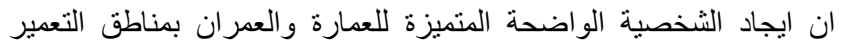

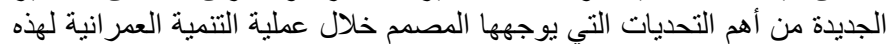
المناطق وخاصة العو اصم حيث الهاب العها مر آة لباقي المدينة. وتعتبر مشكلة افتقاد الطابع إحدى المشاكل الاساسية للعمارة المعاصرة خاصة الهانة

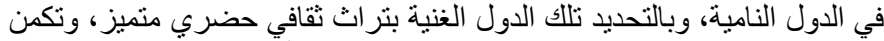

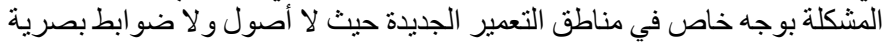

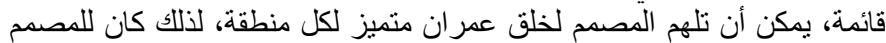
حرية في التشكيل المعماري والعمر اني مما ادي الى خلى خلق عمران منثابهة فاقد

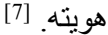

ويعد الهدف من دراسة الهوية العمر انية والمعمارية للمدن القديمة الى رسم

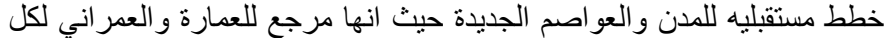
مدينة فهي بمثابة بصمة مختلفة لكل مكان ويمكن ان يكون ذلك على ثلاث محاث الكاول

هامة.

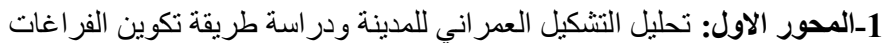

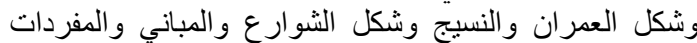

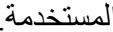

2-المحور الثاني: تحليل الطابع المعماري للمدينة ليكون بمثابة مرجعية للذهن وخلق

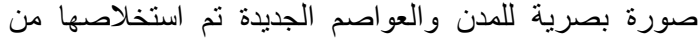

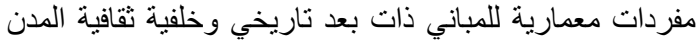

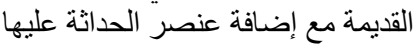

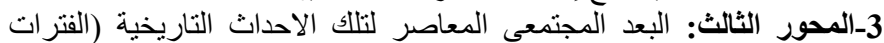

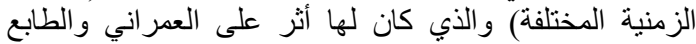

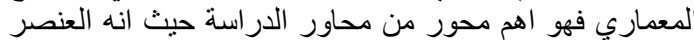

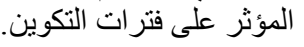

2-2 وظبفة الهوية و الحفاظ عليها [9]

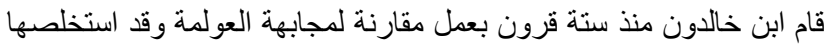

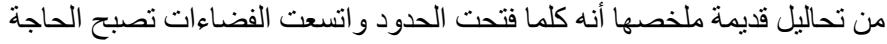

4- استنباط عدة مؤشر ات يمكن من خلالها تقييم العو اصم الجديدة وتطبيقها على (العاصمة الإدارية الجديدة) و الخروج بنتائج و اضحة.

وتأتي أهمية دراسة تأثير الطابع المعماري و العمر اني الى التعرف على أهمية التئية

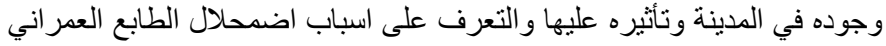

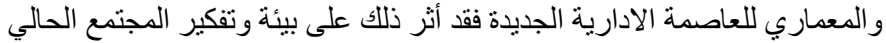

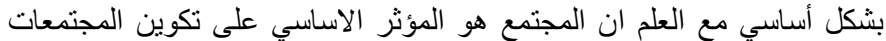

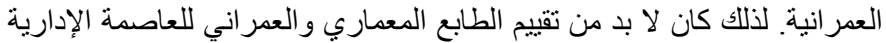

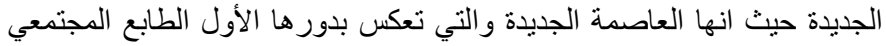

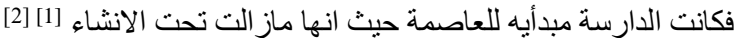

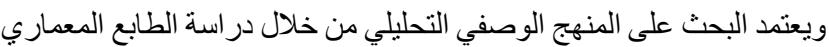

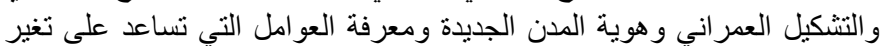

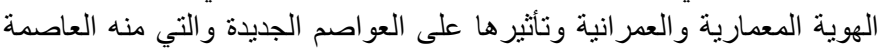

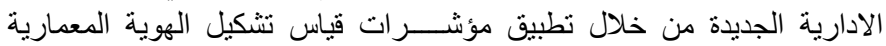
و العمرانية عليها، ومعرفة نسبة تحقق ذللك في العاصمة الجديدة من عدمه الإنة و واستخلاص النتائج. شكل (1) ولنا،

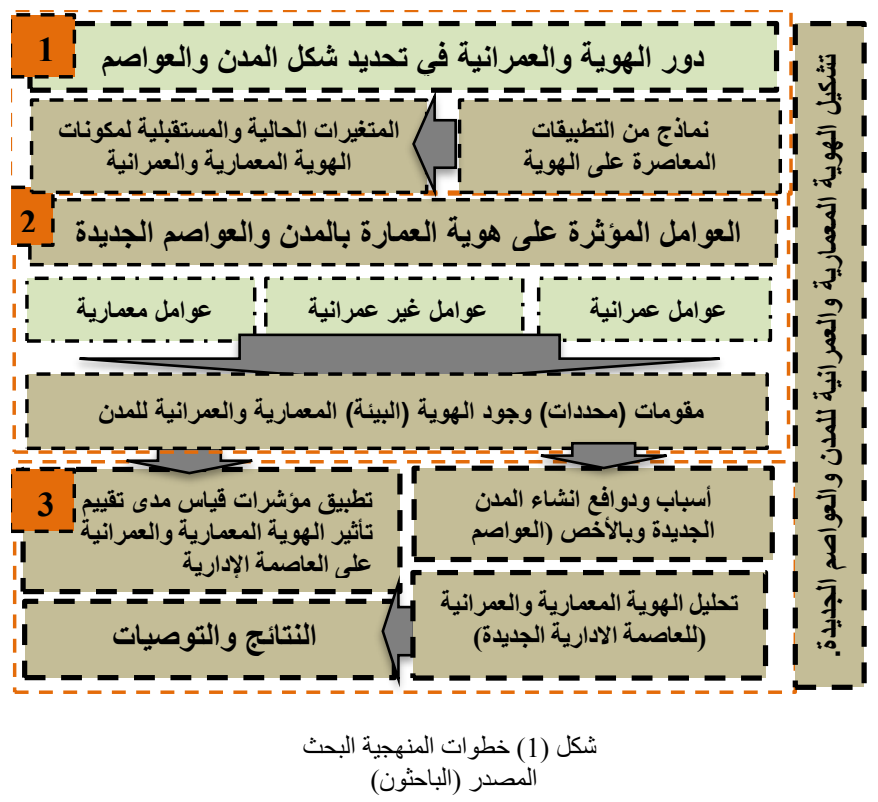

\section{الهوية المعمارية والعمر انية للمدينة.}

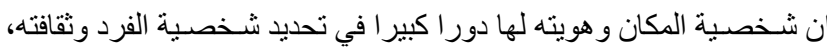

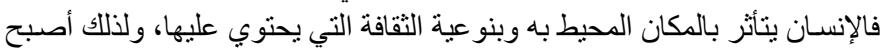

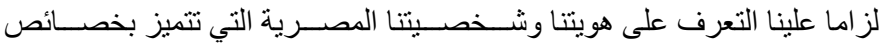

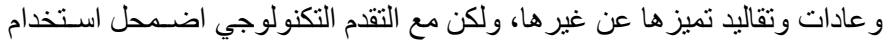
المفردات الدصرية كعنصر اساسي.

ؤولا مفهوم الهوية: يعد مفهوم الهوية من المفاهيم ذات الطبيعة الثناملة و العامة

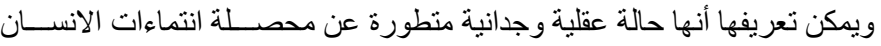

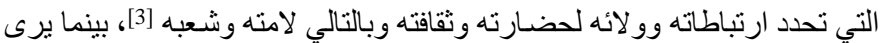

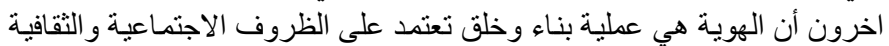

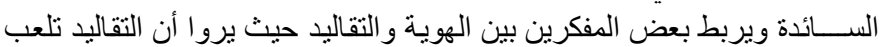

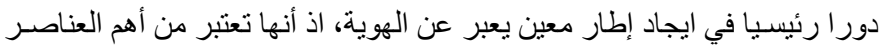

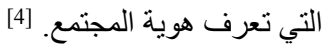




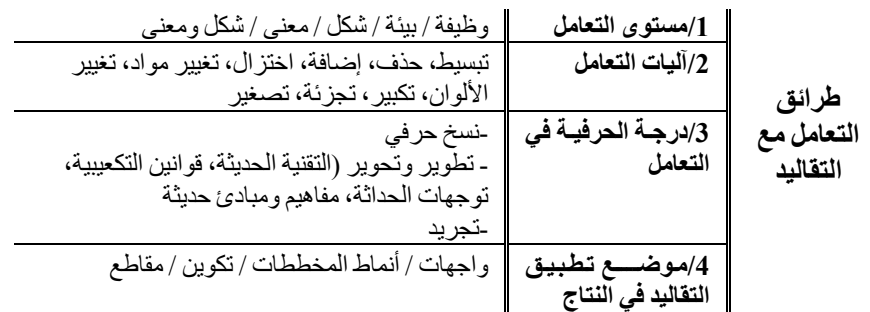

الخطوط الأفقية في الجدول بتوجع المتغيرات الحالية والمستقبلية لمكونات الهوية العمرانية

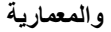

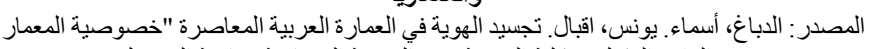

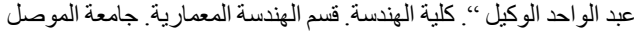

العوامل المؤثرة على هوية العمارة والعمران بالمدن والعواصم الجديدة. و هي تللك العو امل المؤثرة على هوية العمارة و التكوين العمر اني للمدينة وهي

[11] كالتالي

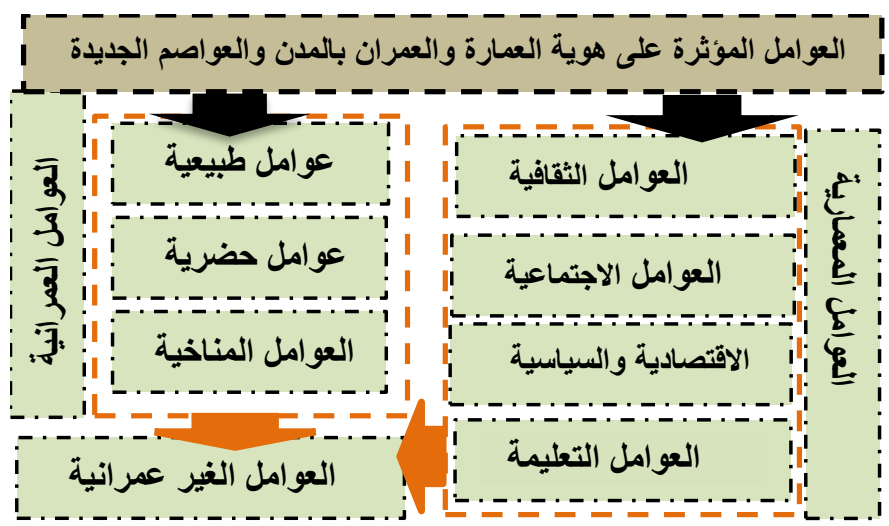

شكل (5) العو امل المؤثرة على هوية العمارة بالمدن الجديدة

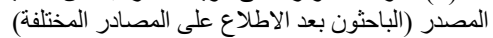

$$
\text { 1-3 111] العو/مل المعدارية }
$$

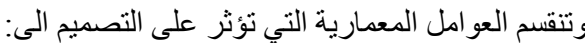

كانت العوامل الثقافية

كانت الثقافة في الماضي معبرة ومرتبطة بتفهم الانسان لأمور دينية وافكار

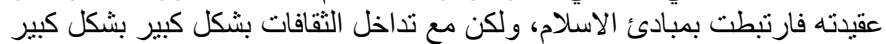

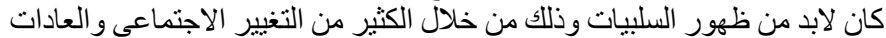

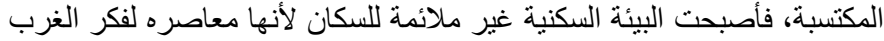
وطبعه.

2-1-3 2-3 العو/مل الاجتماعية

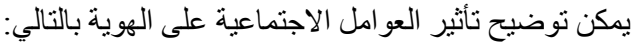
ـادت العمارة التي بنيت لتلبية احتياجات السكان من السكن الي استقلاعل كل اسره

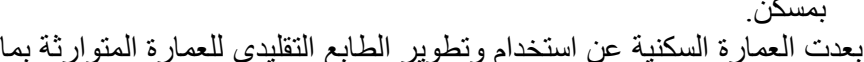

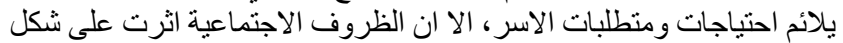

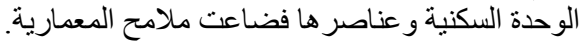

\section{3-1-3 - 3-3 العو/مل الاقتصادية}

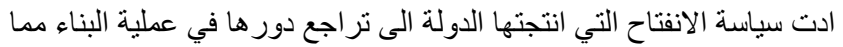

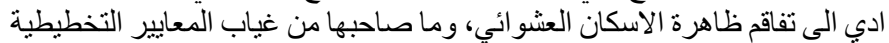

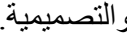

4-1-3 - 2-3 العو/مل السباسية

ـانعكس سوء الادارة على الاعمال المعمارية حيث عبرت عن عمران الكم لا لإنية

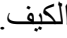

الى الهوية قوية، وبقدر ما بزداد الانفتاح على الاخر تزداد النزعة الى الإحتى الاحتماء

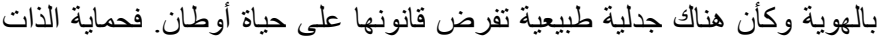

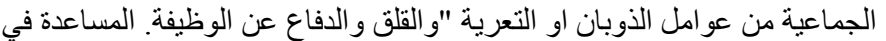

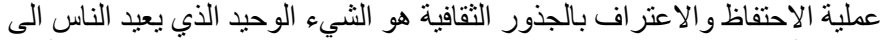

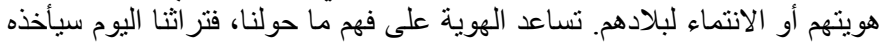

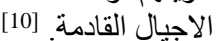

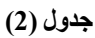

نماذج من التطبيقات المعاصرة على الهوية

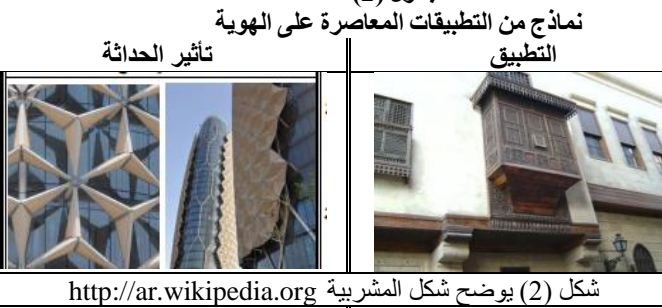

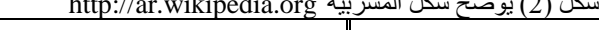

-المشربية (في مسكن) القاهرة - || - المشربية (سكني اداري) -أبراج البحر

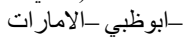

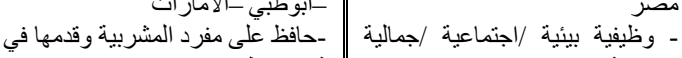

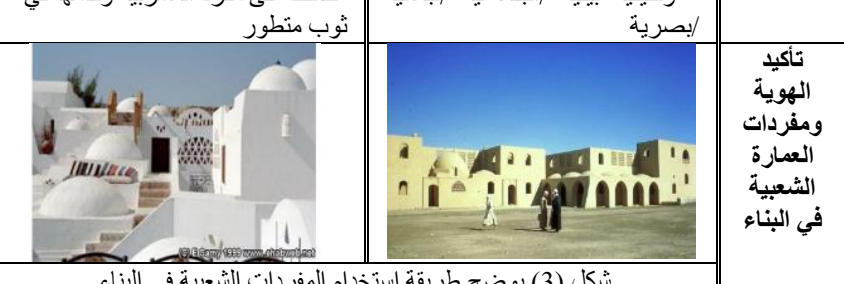

شكل (3) يوضح طريقة استخدام المفردات الثعبية في البناء

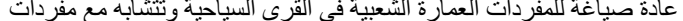

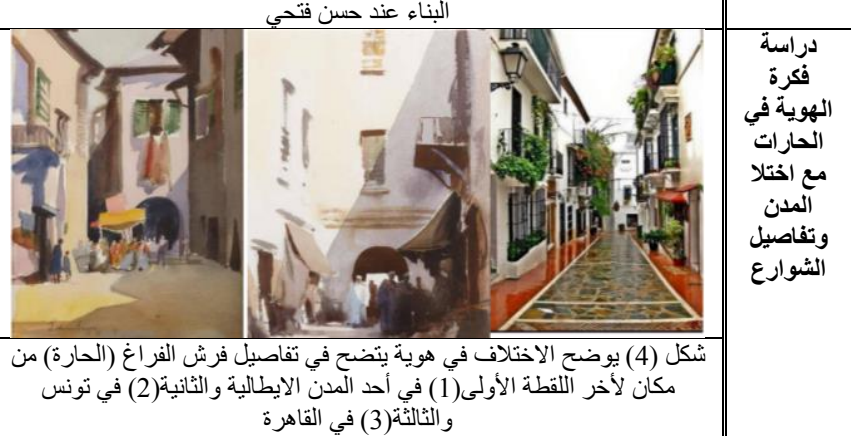

الخطوط الافقية في الجدول بتحدد بعض الأمثلة المعاصرة للهوية وكيف يمكن تطبيقها لعناصر الحداثة

3-2نماذج من التطبيقات المعاصرة على الهوية

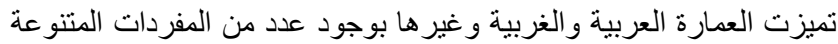

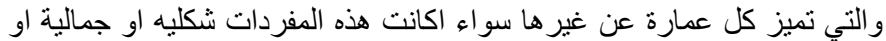

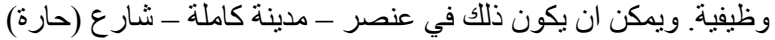

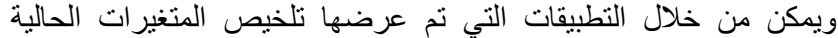

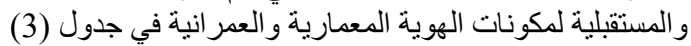

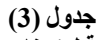

المتغيرات الحالية والمستقبلية لمكونات الهوية المعمارية والعمرانية

\begin{tabular}{|c|c|c|c|}
\hline \multicolumn{2}{|c|}{ 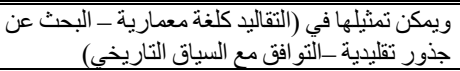 } & 1/الاستراتيجيات & \multirow{6}{*}{ التالتقاليانة التسبيد } \\
\hline \multicolumn{2}{|c|}{ يمكن ان ينقسم الى جزئيين و هما: } & 2/مستوى الاستعانة & \\
\hline 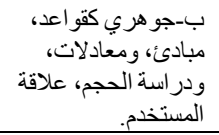 & ألتزيين، اقئ كعناص، & & \\
\hline \multicolumn{2}{|c|}{ كالعصور الإسلامية } & ل للمراجع التقليدية الزمساني & \\
\hline \multicolumn{2}{|c|}{ كالمناطق الإسلامية } & للمراجع التقليدية المــاني & \\
\hline 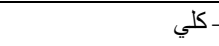 & & 5/ مقدار الاستعانة & \\
\hline
\end{tabular}


التي تنظم العلاقة بين الناس وبعضهم البعض (العو امل الاجتماعية.) ويمكن تحديد

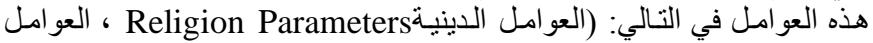

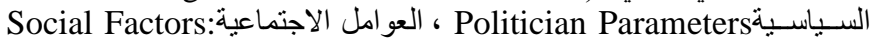

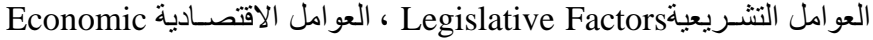

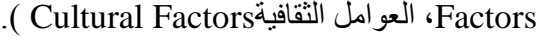

\section{مقومات (محددات) وجود الهوية (البيئة) المعمارية والعمرانية للمدن}

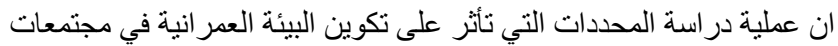

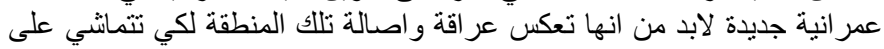

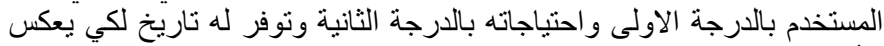

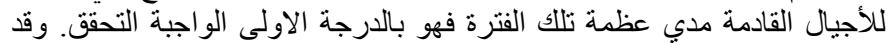
تتمثل تلك المتغير ات في الاتي:

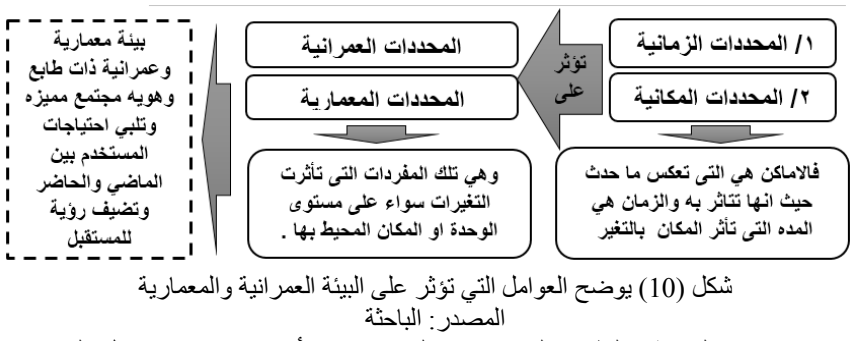

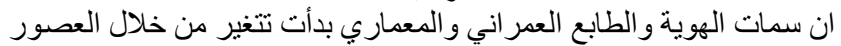

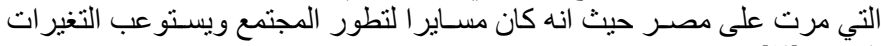
الجديدة [13].

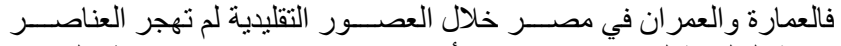

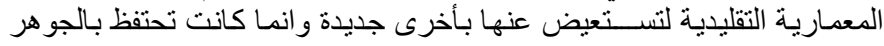
و المضـــمون، وتعبر عن افكار وقيم و عادات المجتمع متناســبة مع البيئة المحيطة
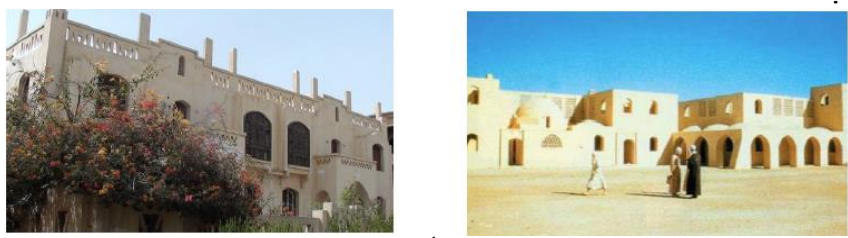

شكل (11) يوضح هوية العمارة المحلية (يمين) أحد المباني العامة التي تم تتفيذها في قرية القرنة

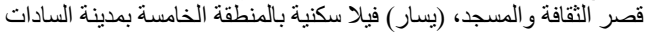
المصدر :المجلة العلمية التخطيط و التنمية جامعة بغداد ـالباحثون.

أسباب ودوافع انشاء المدن الجديدة وبالأخص (العو اصم الجديدة) V تعددت الأسباب التي جعلت من انشـاء العاصمة الجديدة لمصر امر حتميا يصعب تخيل المستقبل بدونه ومن هذه الأسباب:

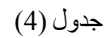

\begin{tabular}{|c|c|c|c|}
\hline تامين تامين السكان & امنبابة & 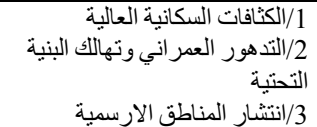 & ع ع اسبابة \\
\hline 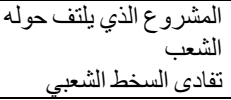 & سباسبة & 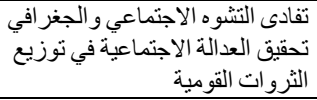 & الاجتماعبة \\
\hline 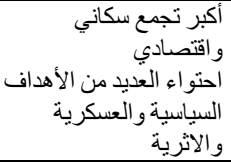 & عسكرياب & 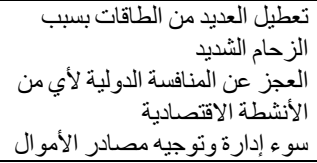 & أستصادية \\
\hline & & 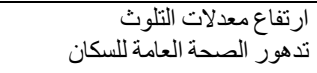 & أسبياب \\
\hline
\end{tabular}

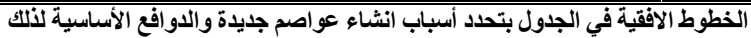

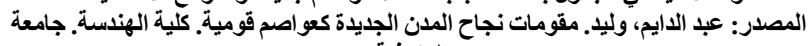

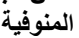

ـأدي ترسيخ المركزية السياسية في العاصمة الى زيادة الهجرة اليها فتكونت

الضو احي العشو ائية بسبب أزمة الاسكان الثديدة. [12]

5-1-3 العو/مل التعليمية

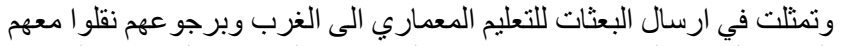

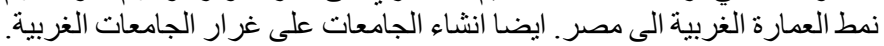

URBAN PARAMETERS 2-3 العوامل العدر/نية وتتقسم العو امل العمر انية التي تؤثر على التصديم التئ

Natural Factors:1-2-3 العوامل الطبيعبة

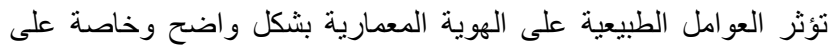

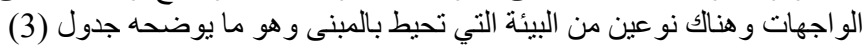

جدول (3) (3) (3)

بحد العوامل الطبيعية التّي تؤُّر على الهوية المعمارية

\begin{tabular}{|c|c|c|}
\hline ثالثا: مبنى يحتوي الطبيعة & ثانظيا: مبنى يتَّاخل مع & وأولا: مبنى يتعايش الطبيعة \\
\hline ت ترتبط بالطبيعة & و هي المباني التي يتم فيها & من حيث التشكيل ومواد \\
\hline هيا الفر اغ الداخليّ بالفر & بعض المدن & \\
\hline
\end{tabular}

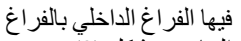

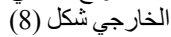
العربيان

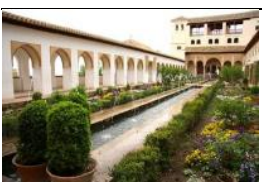

شكل (8 ) يوضح تداخل الطبيعة في المباني بمدينة

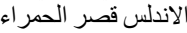
المصدر : الاندل :

AR.WIKIPEDIA.ORG

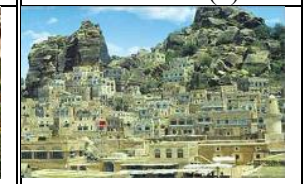

شكل (7) يوضح تداخل المباني في الطبيعة بمدينة الجوف

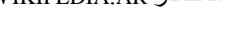

الخطوط العمودية والافقية تحدد العو امل الطبيعية وتأثير ها على العمارة وتم وضع صورة توضيحية لكيفية الثأثير

2-2-3 - 2-3 البيئة الحضرية:

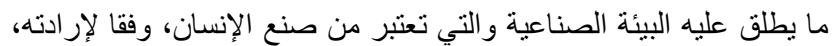

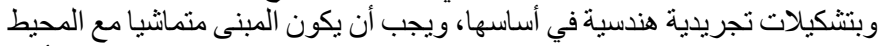

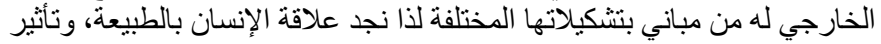

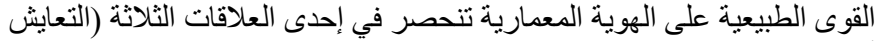

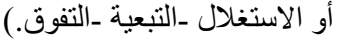

Climate Parameters 2-2-3 العوامل المناخية

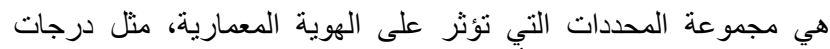

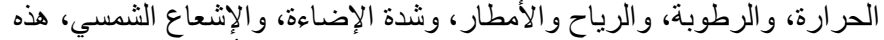

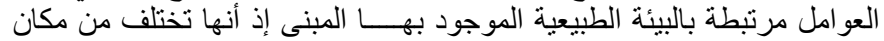

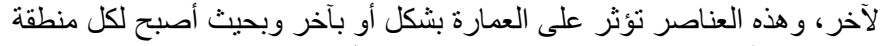
طابع مميز لها عن غير ها كما هو موضي العنح في شكل (9).

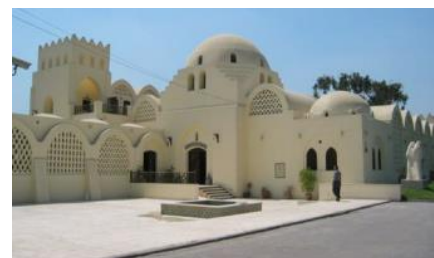

شكل (9) يوضح تأثير العوامل المناخية على هوية المبني (البروزات والأقبية بالمناطق الحارة)

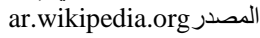

3-3 العوامل الغبر عمرانية (العوامل الإنسانية HUMAN PARAMETERS)

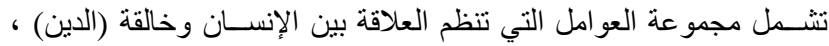

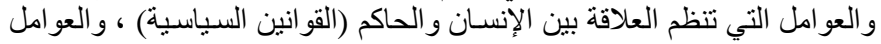




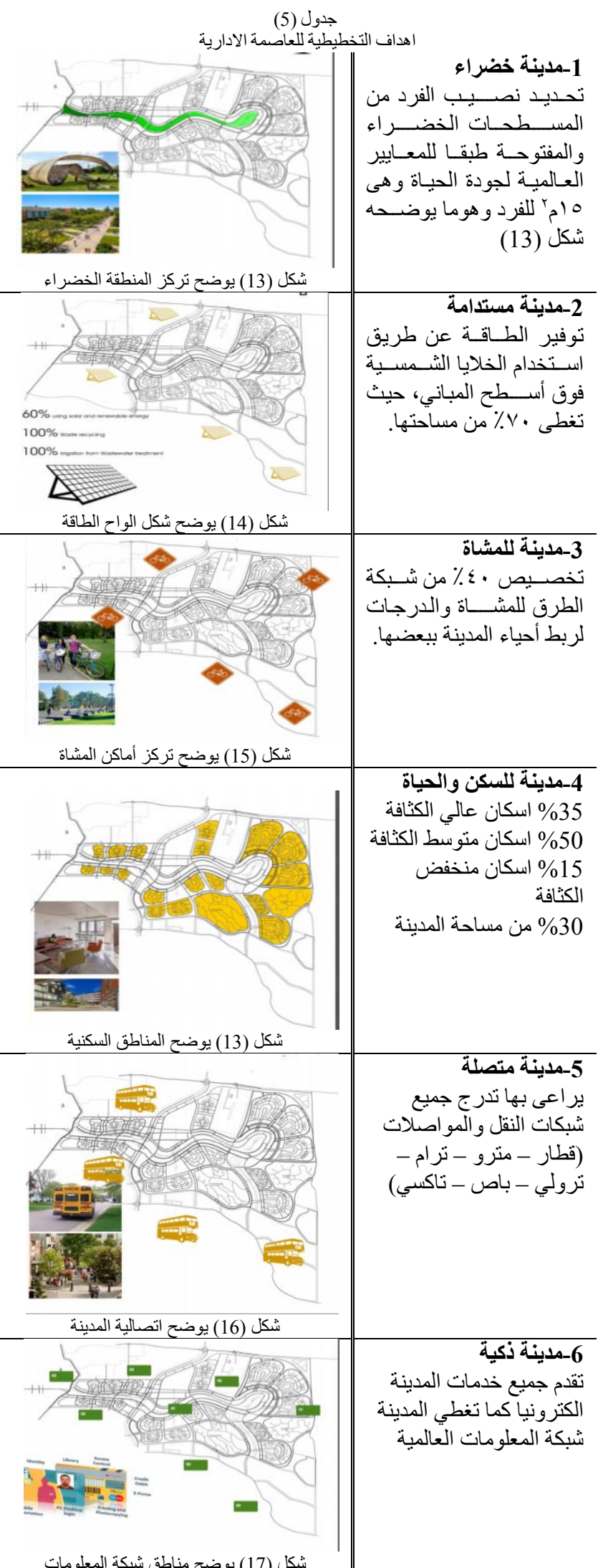

http://admin.mhuc.gov.eg//Dynamic_Page/636651628631802507.pdf الخطوط الافقية تحدد الأهداف التخطيطية للعاصمة وتوضح إثر تلك الهدف على العدينة وأماكن تواجده
تحليل الهوية المعمارية والعمرانية (للعاصمة الادارية الجديدة) VI أولا : موقع العاصمة الإدارية:

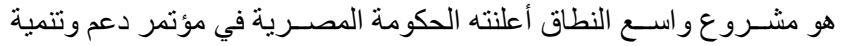

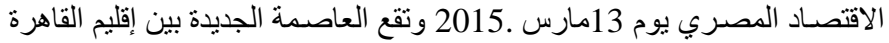

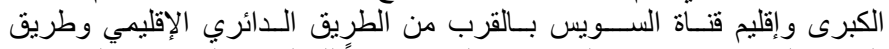

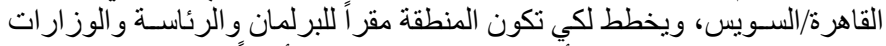

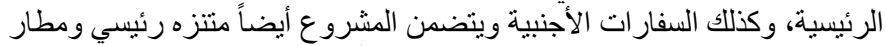

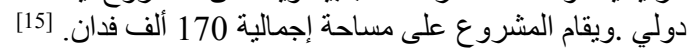

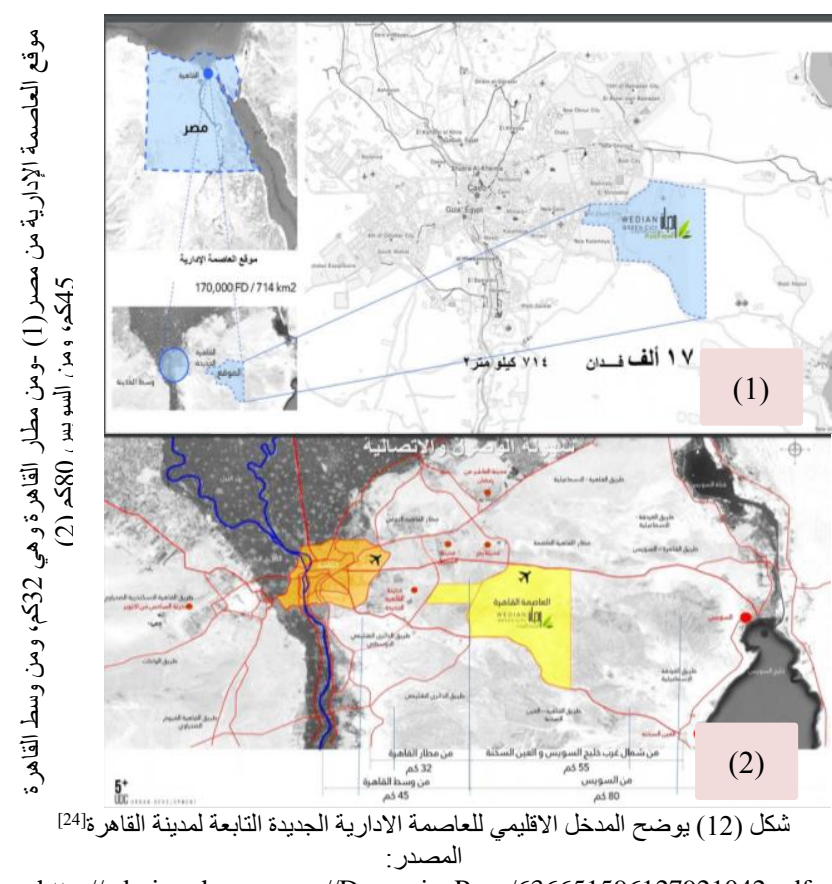

http://admin.mhuc.gov.eg//Dynamic_Page/636651596127921042.pdf

ثانيا: الطابع الهعداري والعدرانسي للعاصمة الادارية الجديلة: -

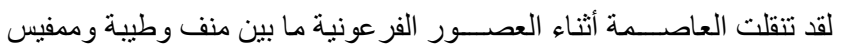

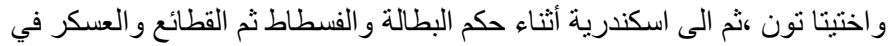

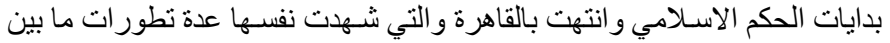

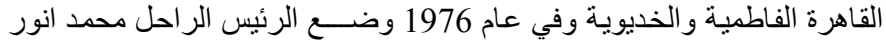

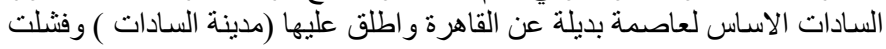

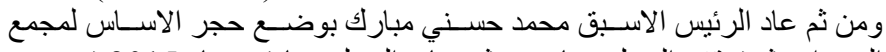

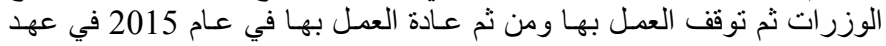

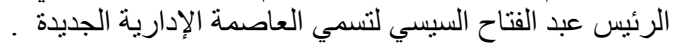

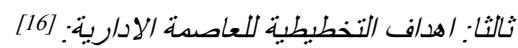

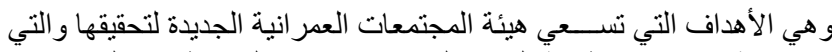

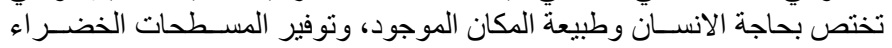

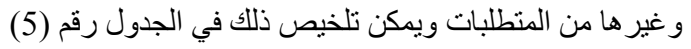

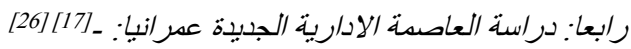

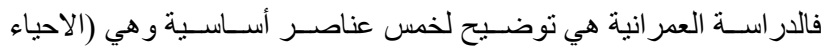

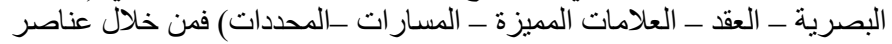
كيفين لينش يتم توضيح التشكيل العمر اني للعاصمة الإدارية الجديدة وفهم الخريطة

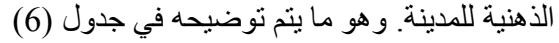

$$
\text { خامسا: دراسة العاصمة الادارية الجديلة معداريا: - }
$$

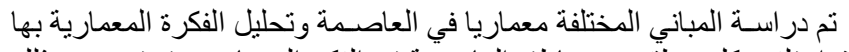

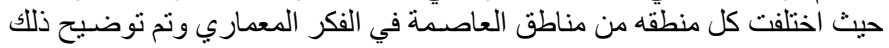

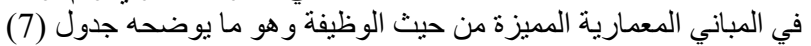


تقع على حدود مدينة بدر في المنطقة المحصورة بين طريقي القاهرة

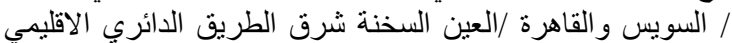

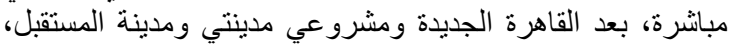

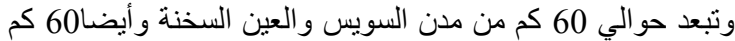

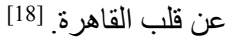
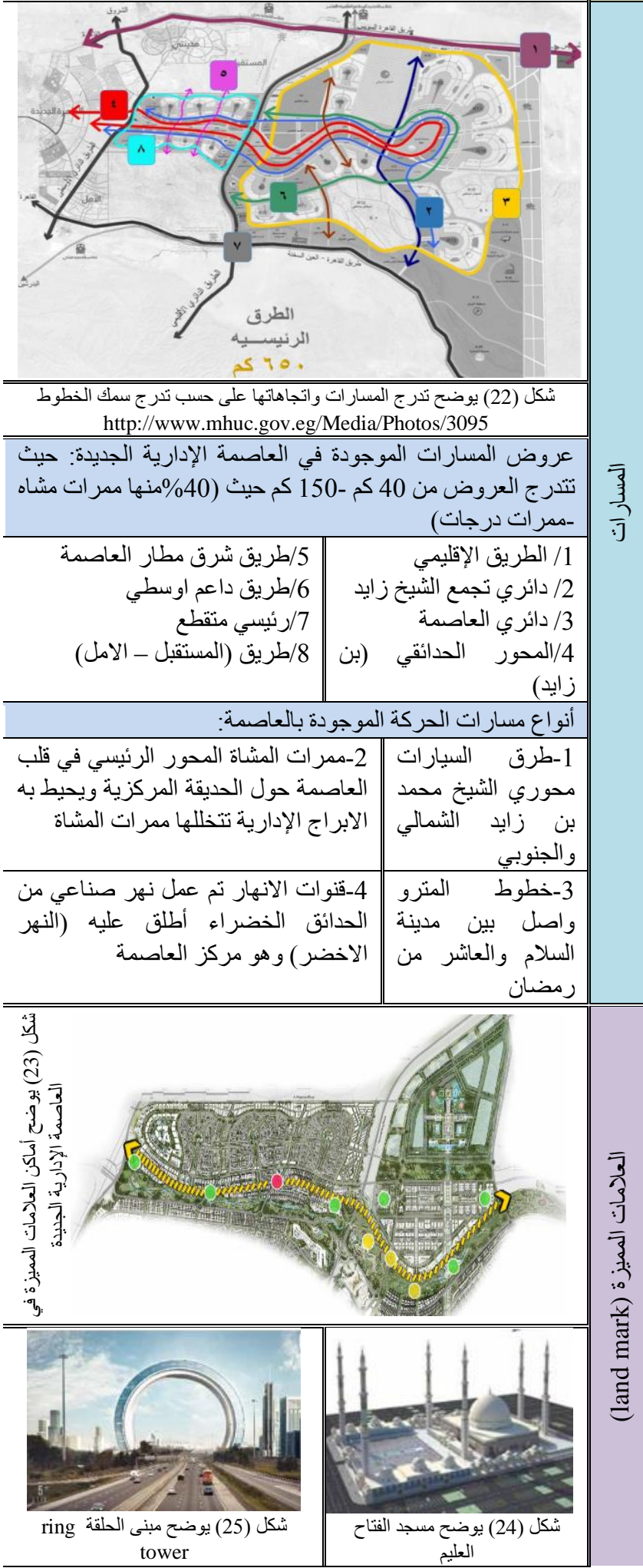

جدول (6) (لالادا التحليل العمر اني للعاصمة الإدارية الجديدة

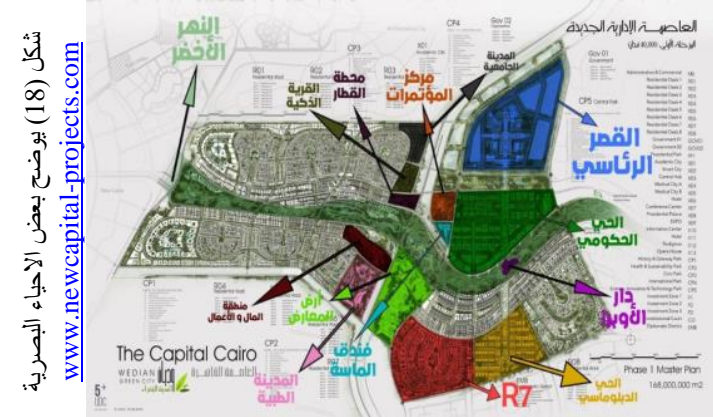

3
3
$\overline{7}$
3
$\overline{3}$
$\overline{3}$

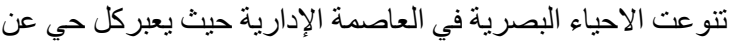

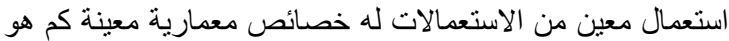

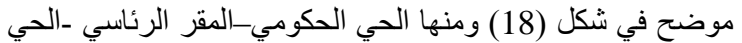

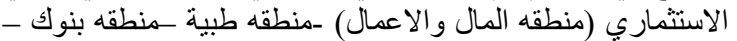
مدينة ترفيهيه - مدينة المعارض)
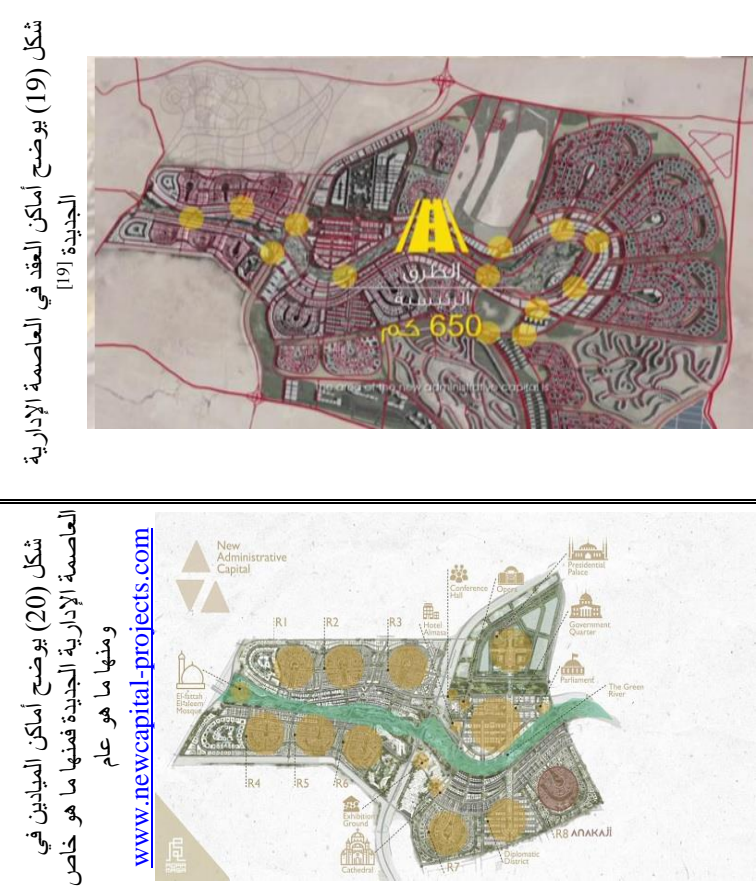

ـالعقد و هي المناطق التي تنتج عن تقاطعات الطرق فينتج تجمع تتكون

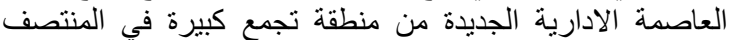

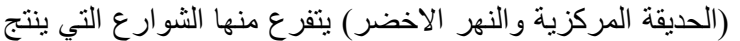
من تقاطعها -ميادين متفرقة تحيط بالمباني الهامة مثل: -ميدان الاوبر ا-منطقة الوزر اء - ساحة المعارض - المدينة الذكية ـالمناطق السكنية.

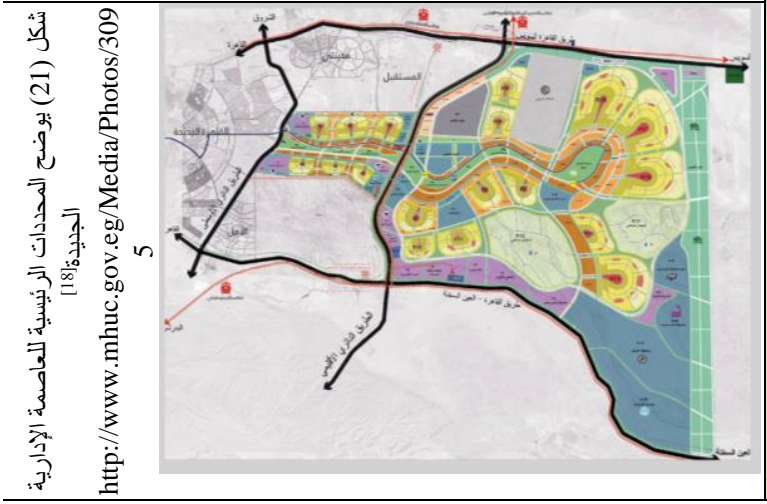


2/1/استبيان حول الهوية الدعمارية في العاصدة الإدارية الجديلة.

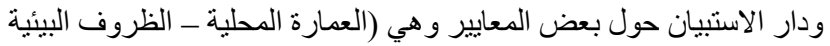

ـ المفردات المعمارية - مواد التثطيب - الثقافة المجتمعية ـ تأثير الحداثة).

اللهوية المعمدارية في اللعاصدمة الادارية الجدديدة

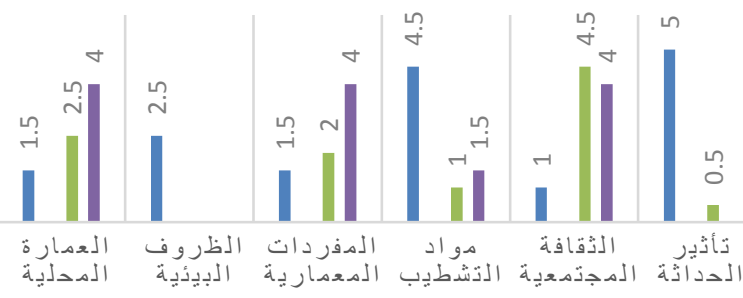

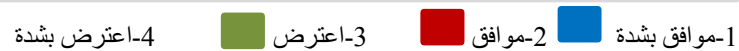

ودار الاستبيان حول بعض المعايير وهي (تأثير المجتمع - مو اكبة العصر )

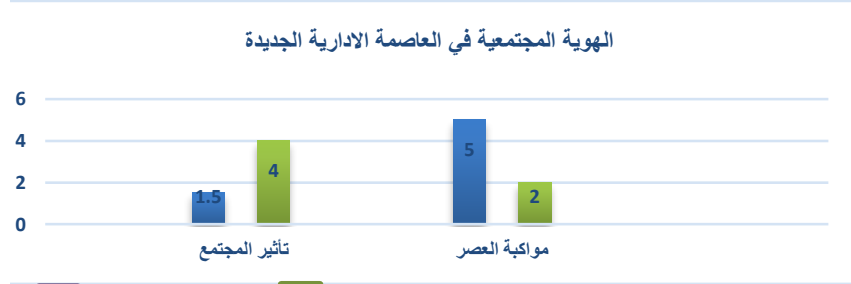

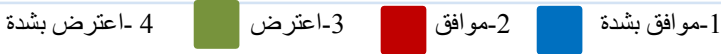

تم عمل استبيان أبضا لسنتة مؤشرات أساسبة:

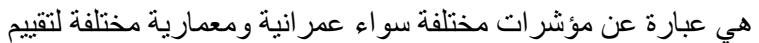

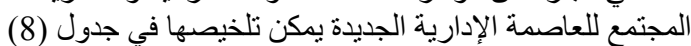

جدول (8) (8)

مؤشرات مختلفة سواء عمرانية او معمارية لتقييم العاصمة الإدارية الجديدة

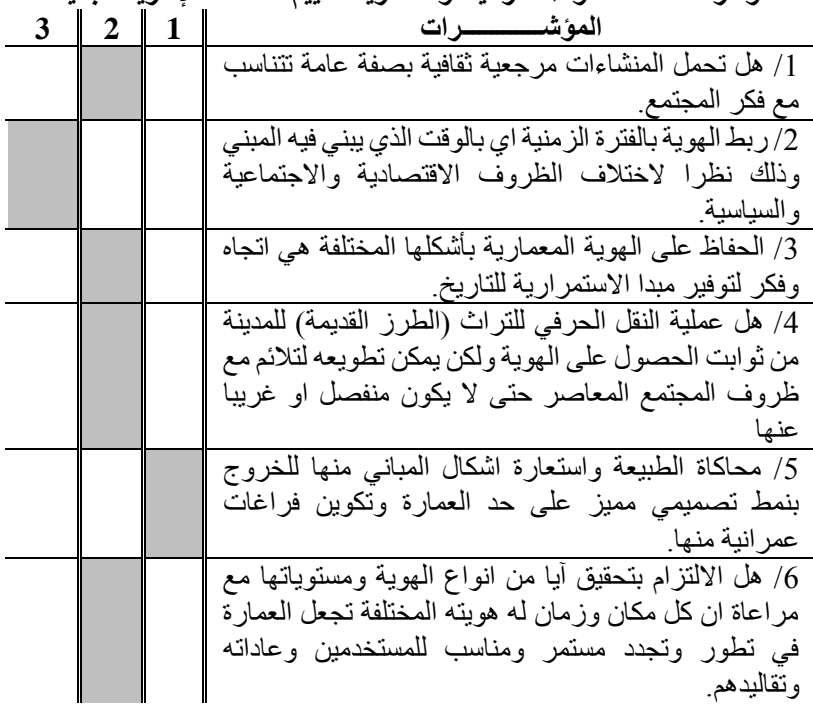

الخطوط العمودية بها المؤشرات المعمارية او العمر انبة الخاصة بتقييم العاصمة الإدارية الجديدة على ثلاثة تقييمات و هي: 1-نعم تم تطبيقها

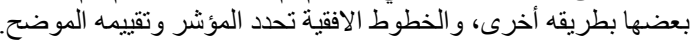

من خلال الاستبيان توضتح التالمي:

$\checkmark$ التصميمات الحديثة.

لم يتم نقل أبي من الهوية التاريخية والطرز القديمة الى المدينة لإحياء نر اثها

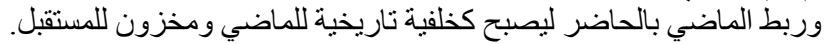

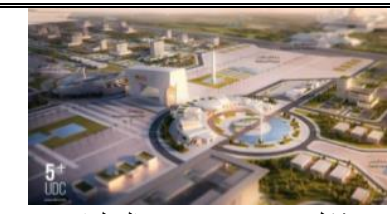

شكل (27) يوضح مبني البرلمان

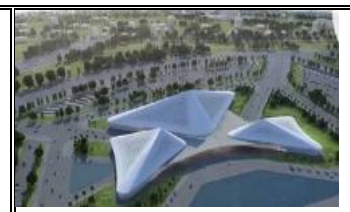

شكل (26) يوضح مركز

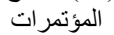

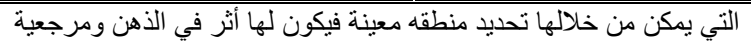

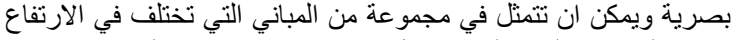

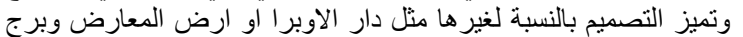

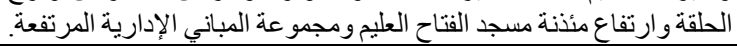

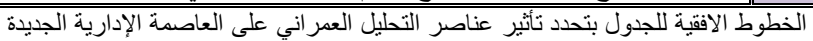
بينما تحدد الخطوط الر أسية العناصر الخريطة الذهنية لــ (كيفين لينش) لتحليل المدينة.

جدول (7) (7) (ل)

تحليل لبعض الأفكار المعمارية في العاصمة الإدارية الجديدة

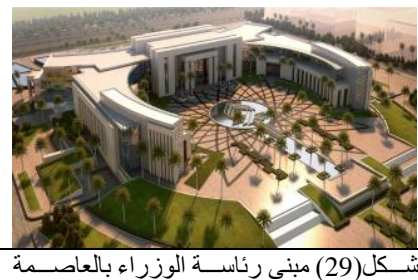

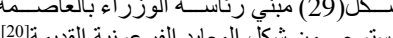

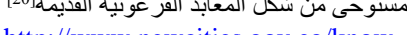
http://www.newcities.gov.eg/know_ cities/alameen new.aspx

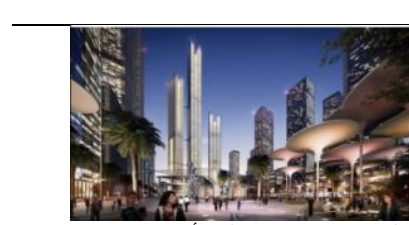

شكل (31) يوضح شكل الأبر اج مستوحى من الأبر اج على مسار كورنيش القاهرة

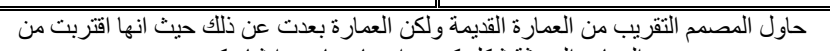
العمارة الحديثة شكل كبير وايضا بعناصر انثاء كبيرة

سادسا: تحليل العاصمة الادارية الجديبة على حسب /ستبيان تم طرحة واستنتاج التنالي س12]

انقسمت الفئة المستهدفة لعمل الاستبيان الى جزيئين وهما:

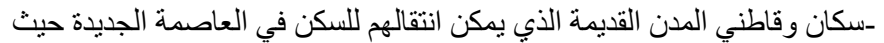

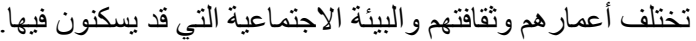

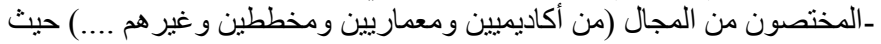

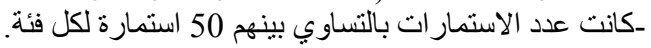

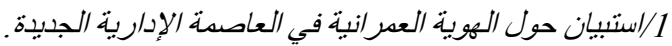

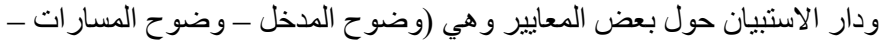

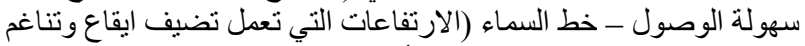
للمكان) - علاقة المبني بالمحيط - تأثير الاستعمالات على المات العيط)

الهوية العمر انية في العاصمة الادارية الجديدة

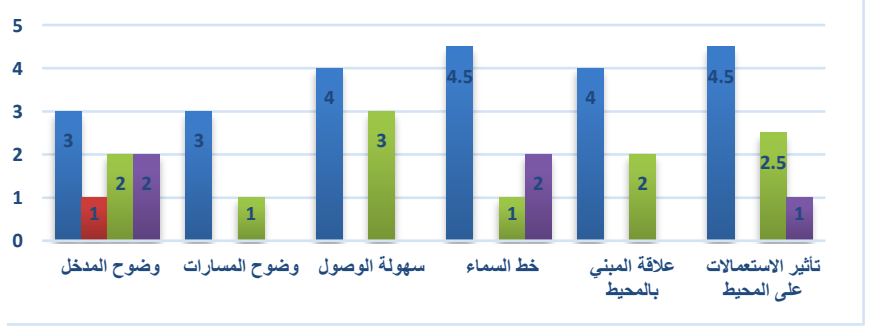

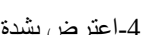

3 - اعترض

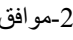

- مو افق بشدة 
VIII الجايدة.

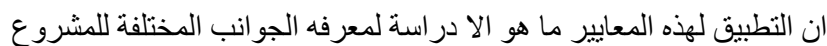

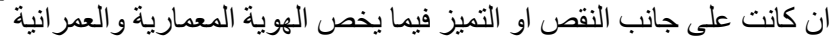

ـ مؤشرات قياس الهوية المعمارية للعاصمة الادارية الجديدة:
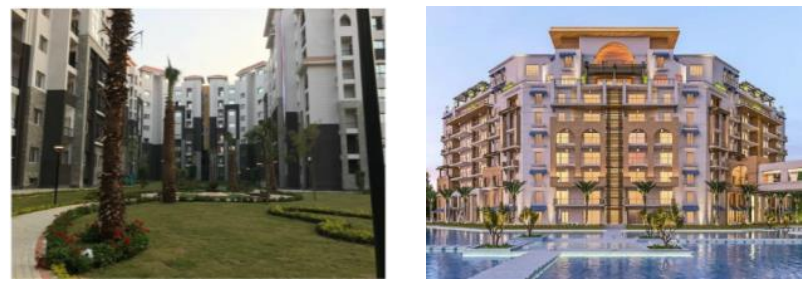

شكل (32) يوضح التركيب المعماري للعاصمة الإدارية الجديدة

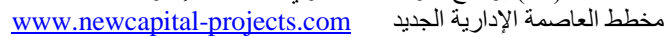

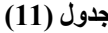

مؤشرات قياس الهوية المعمارية للعاصمة الادارية الجديدة

\begin{tabular}{|c|c|c|c|c|c|}
\hline \multicolumn{3}{|c|}{ التقييم } & التأثير والمردود على العاصمة الادارية & \multirow{2}{*}{\multicolumn{2}{|c|}{ المؤشرات }} \\
\hline 3 & 2 & 1 & & & \\
\hline & & & 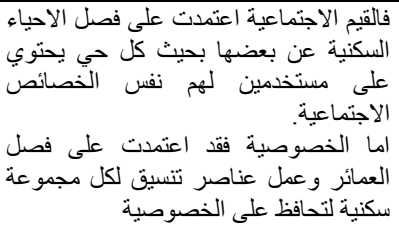 & والخيم الاجتماعية & 辛. \\
\hline & & & 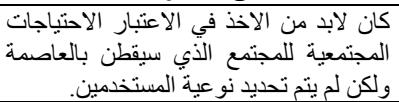 & و الالنعداني المجتمعي & \\
\hline & & & 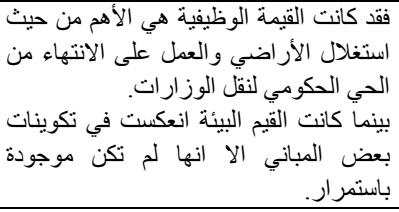 & و البيئية & \\
\hline & & & 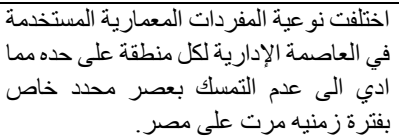 & البناصر المعمارية & \\
\hline & & & ذات استعمالات مختلفة. للتفيذ الان ومر احل مستقبلية & الامستقبلي & 可 \\
\hline & & & 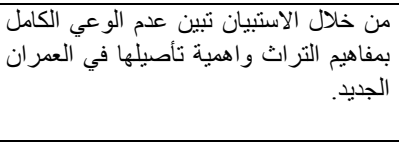 & 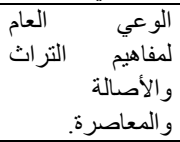 & 手 \\
\hline & & & 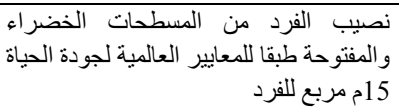 & المعالجات البيئية نظم & : \\
\hline & & & 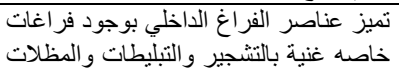 & تصاخليخ & 可 \\
\hline & & & فر اغيرها من عناصر التتسيق وتصب على النهر الاخضر & الداخلي & \\
\hline & & & والحكو منية التكوينات السكنية والتجارية & التكوين المتر ابط & 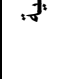 \\
\hline & & & 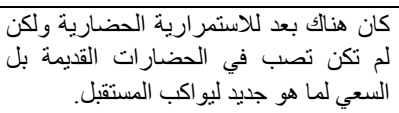 & العضد الاستمر ارية & \\
\hline
\end{tabular}

الخطوط الأفقية و العمودية نوضح تطبيق المؤشر ات على العاصمة وهي بثلاثة تقييمات وهي:

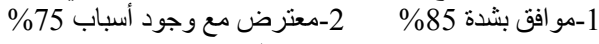

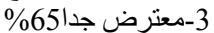

هناك مباني محاكاة للطبيعة من حيث التكوين و التشكيل ولكن اقتصر وجودها على مناطق معينة.

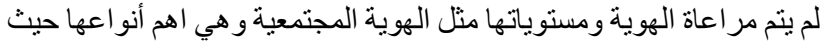

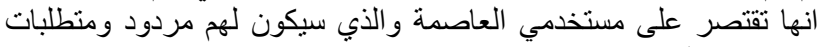

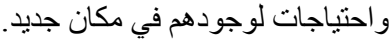

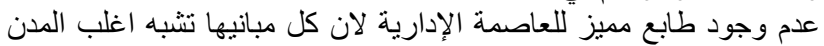

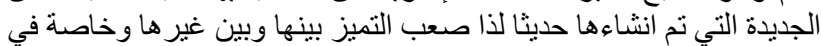

الاحياء السكنية منها.

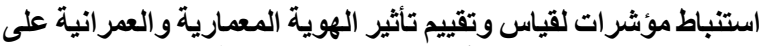

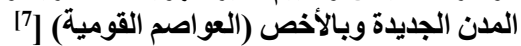

\section{VII}

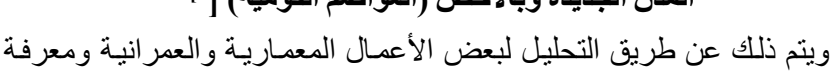

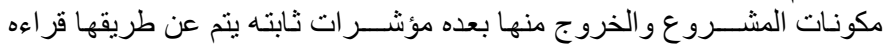

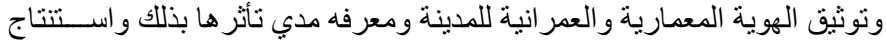

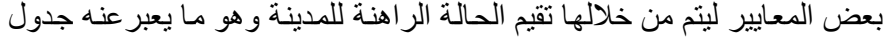

[23] [22] (10) (9)

\section{جدول (9) (2)}

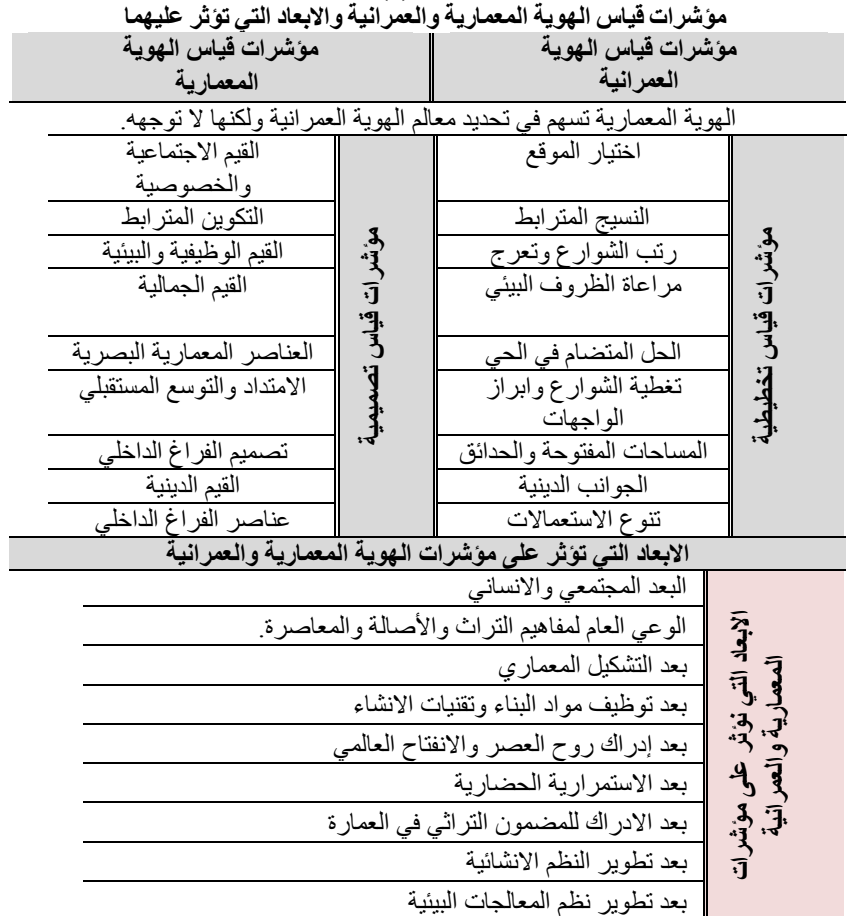

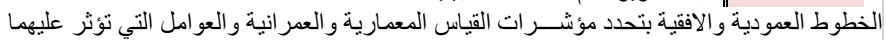

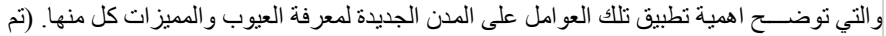
تقسيم الجدول الى جدولين للتطبيق على العاصمة الجديدة)

$$
\text { ـ مؤشرات التصسيم البيئي: - }
$$

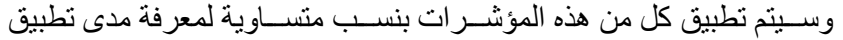

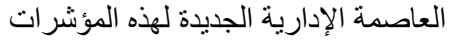
جدول (10) (10)

مؤشرات التصميم البيئة (مبادئ العمران الجديد)

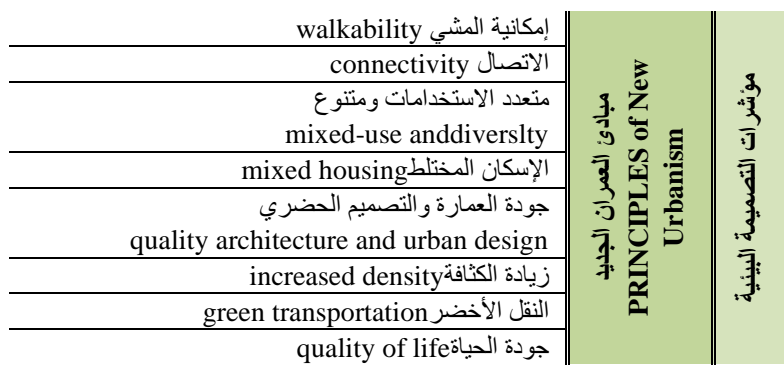

الخطوط الافقية توضح مؤشر ات التصميم البيئي (مبادئ العمر ان الجديد) 


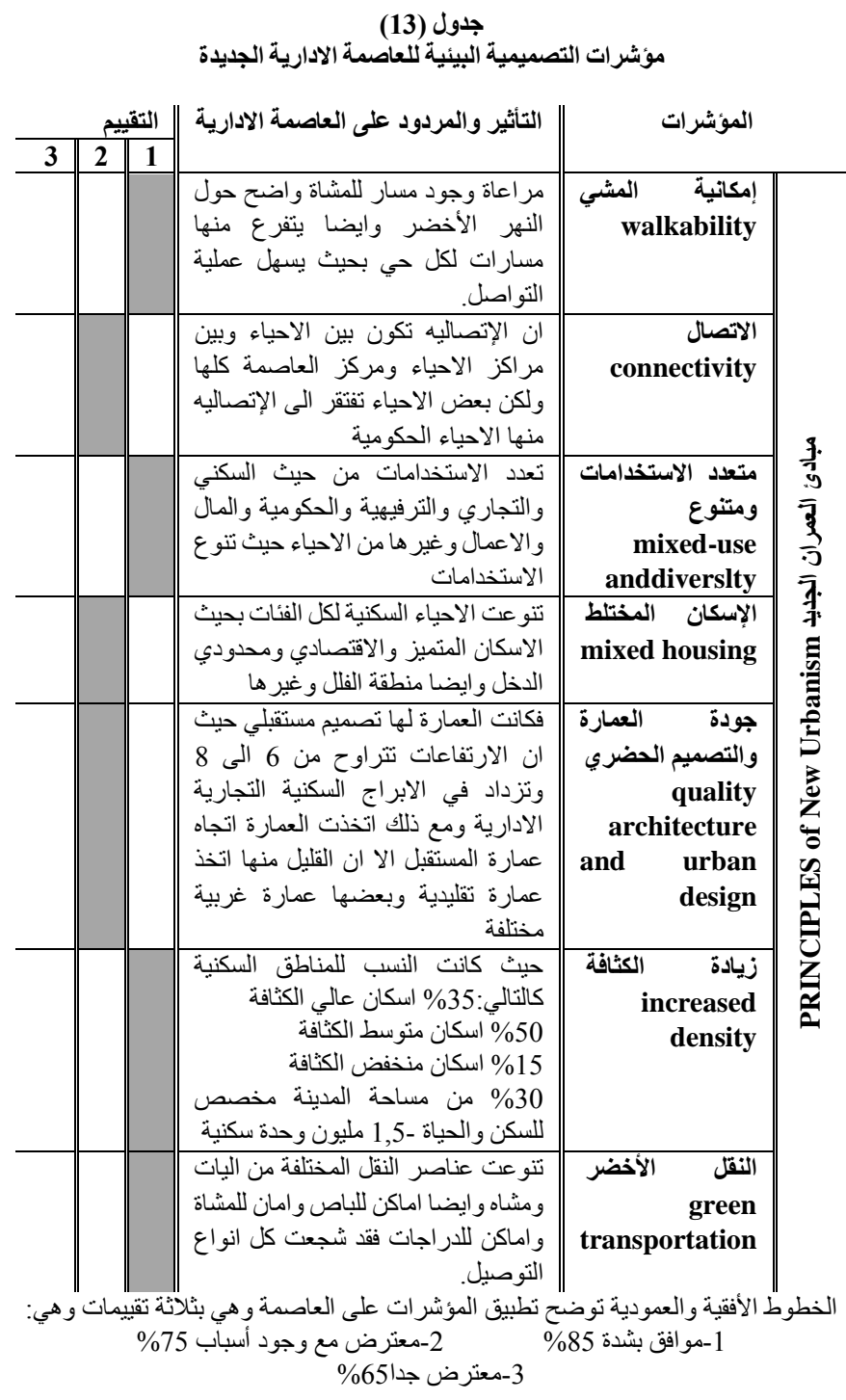

ـ مؤشرات القياس التصميمية البيئية للعاصمة الادارية الجديدة:

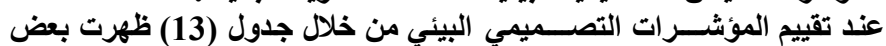

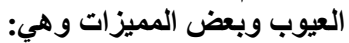

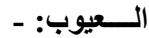

ــلم يتم مر اعاة مسافة السير بين الاستعمالات مثل المناطق السكنية و التجارية.

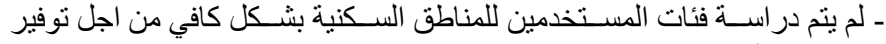

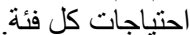

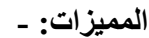
-جميع مع ذكر في الجدول مما كان تقييمه 85\%.

\section{IX}

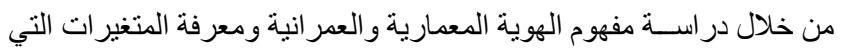

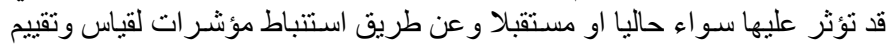

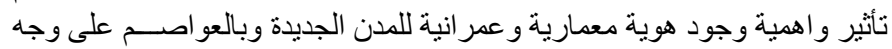

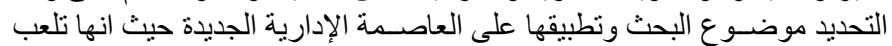

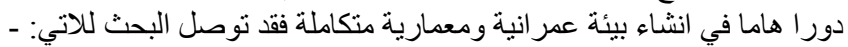

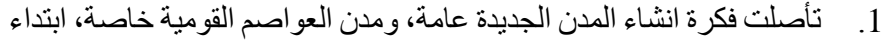

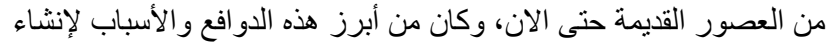

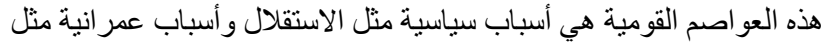
احتقان العاصمة القديمة وأسباب اجتماعية مثل العمل على العيل إعادة تتكيل

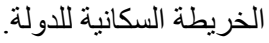

عند تقييم مؤشرات الهوية المعمارية من خلال جدول (11) ظهرت بعض العيوب

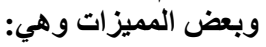

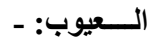
ـاهم العيوب الموجودة عدم الدارسة الكافية لهوية المستخدم وذللك لان الدراسة لم لفئل تكتمل بعد لعدم الانتهاء من العاصمة الإدارية الجدئ الجيدة.

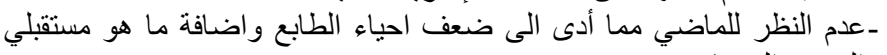
و التوجيه الى ما هو جديد. ـ ضعف الترابط البصري بين كل حي و الأخر ادي الى اختلاف كل حي عن الاخر

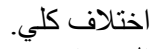

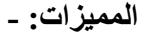

جميع مع ذكر في الجدول مما كان تقييمه 85\%.

جدول (12) (12)

تطبيق مؤشرات قياس الهوية العمرانية للعاصمة الادارية الجديدة

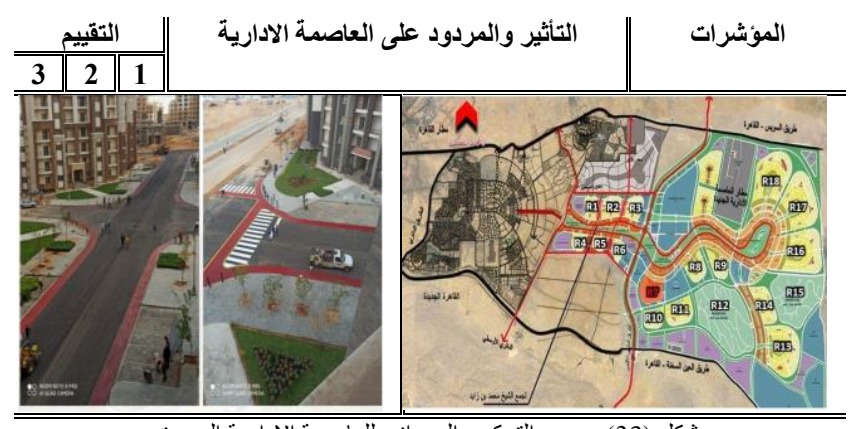

شكل (33) يوضح التركيب العمر اني للعاصمة الإدارية الجديدة. WwW.newcapital-projects.com

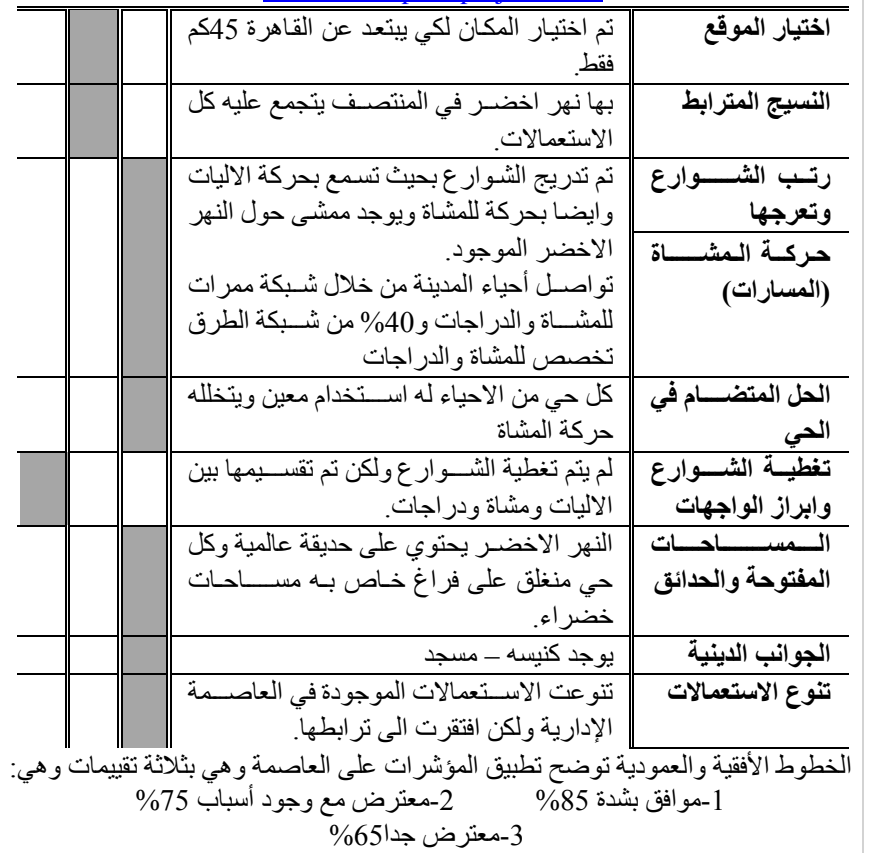

ـ مؤشرات قياس الهوية العمرانية للعاصمة الادارية الجديدة: عند تقييم مؤشـرات الهوية العمرانية من خلال جدول (12) ظهرت بعض العض العيوب

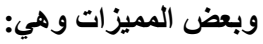

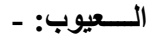

ـاختيار الموقع يبعد عن مدينة القاهرة بالتالي كان من الصـعب انتقال السكان اليها. و الموازنة بين المسكن و العمل.

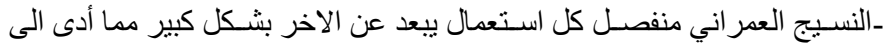
صعوبة الوصول والاتصالية بينهم. لملم يتم تغطية الثو ارع مما ادي لعدم التأقلم مع طبيعة المكان وتوفير الراحة.

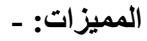
جميع مع ذكر في الجدول مما كان تقييمه 85\%. 


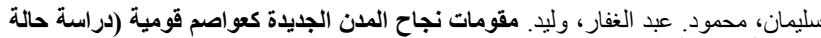

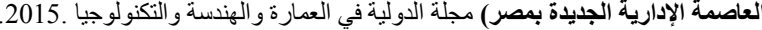

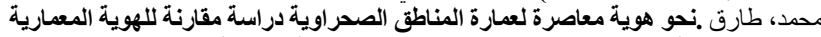

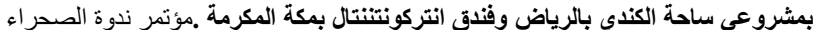

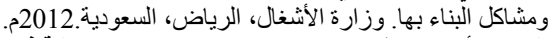

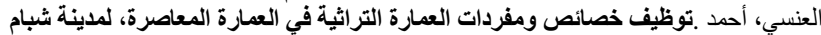

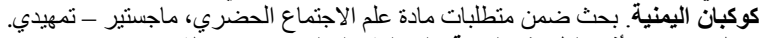
صالح، يحيى .تأثير الظروف البيئية على التثكيل المعماري. رسألة دكتور اهنية غير منشورة. كلية

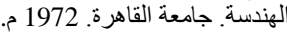

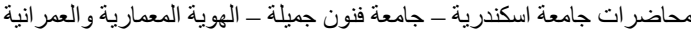

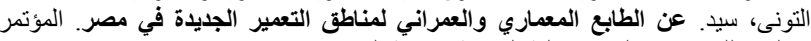

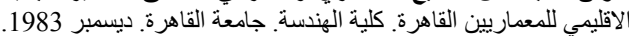

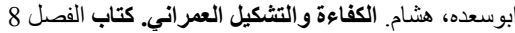

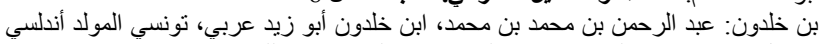

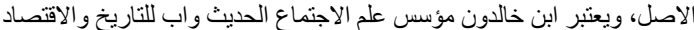

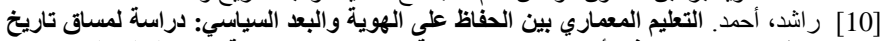

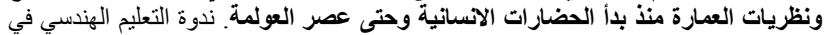

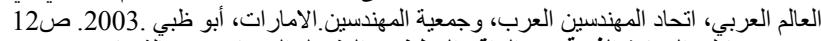

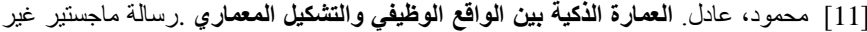

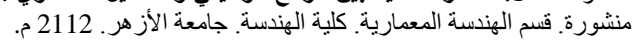
http//www.oman0.net /showthread.php?t=432742 (2011) [12] [13] مصطفي، صالح. تحديات التوسع العمراني -حالة القاهرة. الندوة التاسعة في سلسلة ندوات عن التاني

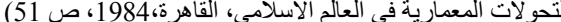

[14] طقطق، جاكلين. دور التصميم المعماري والعمر اني في تنمية الثعور بالاتنماء في أطار التطور

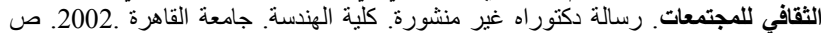

http://www.newcities.gov.eg/Default.aspx هيئة المجتمعات العمرانية الجديدة] [15] http://admin.mhuc.gov.eg//Dynamic_Page/636651628631802507.pdf [16] http//www.oman0.net/showthread.php?t=432742 (2011) [17]

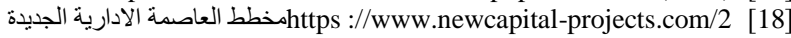
http://www.mhuc.gov.eg/Media/Photos/3095 [19] https://www.sis.gov.eg/Story/132575?lang=ar [20] http://www.newcities.gov.eg/know_cities/alameen_new.aspx [21] [22] محسن، عبد الكريم. صيدم، محمود. احياء القيم المعمارية التراثية في العمارة المعاصرة لمدينة

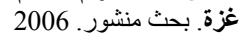

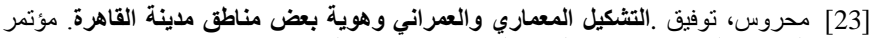

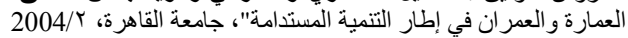

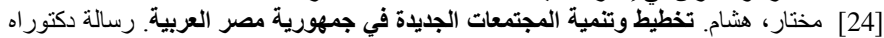

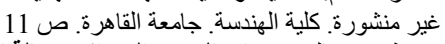

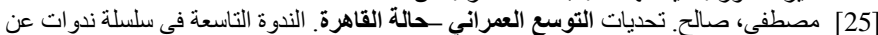

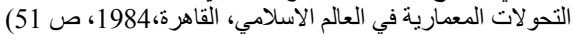

Abo El-Enyen, Essam. Atwa, Mohammed. Abo Samra, Noha. [26] FEATURES OF THE URBAN FORM FOR WATERFRONT ZONES CASE STUDY: THE URBAN FORM ALONG SUEZ

CANAL. Journal of Engineering Sciences, Assiut University, Vol. 36.2008. pag551,553

http://admin.mhuc.gov.eg//Dynamic_Page/636651596127921042.pdf [27] وزارة الإسكان و المر افق $\mathrm{Http} / / \mathrm{www}$ ar.wikipedia.org. [28] [29] الفقي، عبد المنعم. الادارة البيئية للعمران الحضري. رسالة ماجستير. كلية هندسة. عين

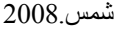

\section{Title Arabic:}

\section{التثكيل المعماري والعمر اني لهوية المدن الجديدة (دراسة حالة العاصمة الإدارية الجديدة)}

\section{Arabic Abstract:}

يعد التشكيل المعماري والعمراني لهوية المدن من المتطلبات الأساسية اللازمة نتيجة

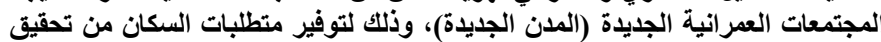

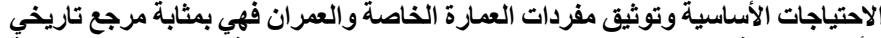

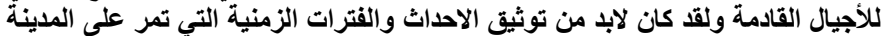

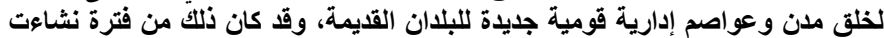

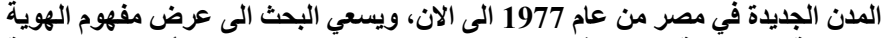

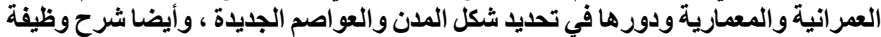

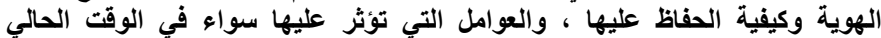

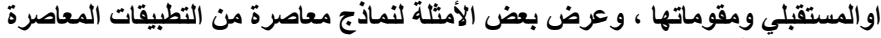

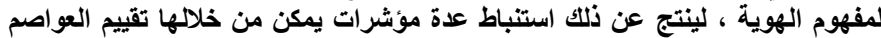

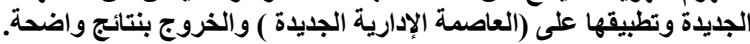

تختلف مناطق العاصمة الإدارية الجديدة من حيث تشكيل الهوية العمرانية

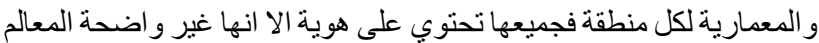

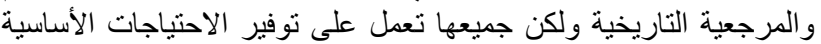

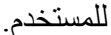

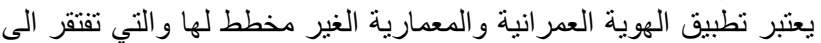

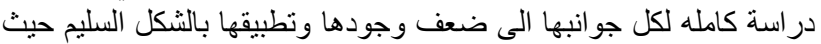

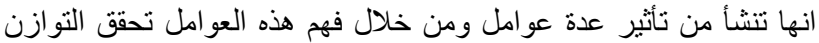

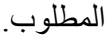

من خلال دراسة التطور العمر اني للعاصمة القديمة ورصد التغير ات في كل

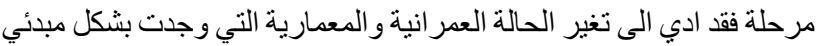

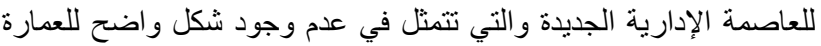
والعمران فيها نتيجة اختلاف الطوابع والانماط والتئ والاتجاهات العمر انية و المعمارية المحيطة بها.

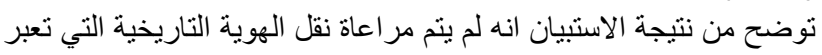

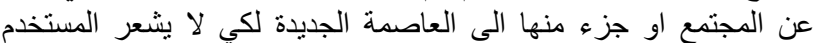
بالاغتر اب مثل فكرة الحار ات القديمة.

\section{X}

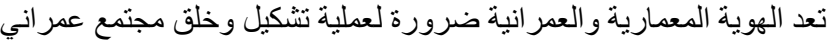

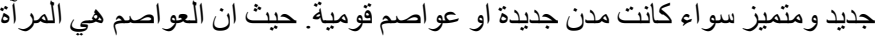

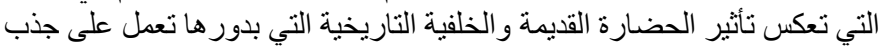

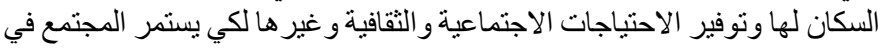
مو اكبة المستقبل لذلك كان من الضرورة الإهان مر اعاة النقاط التالية حتى يمكن تحقيق هذه

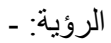

1. لابد من توفير اليات يمكن من خلالها تحقيق الاهداف التخطيطية للعاصمة

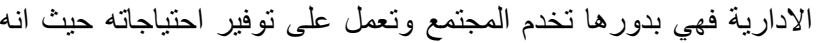
المكون الأساسي في خلق مجتمع ذو هوية وثقافة تنعكس على البيئة المحيطة.

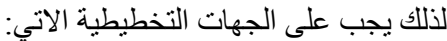

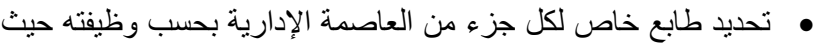

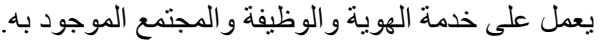

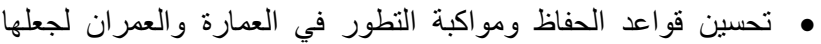

تستو عب المتغير ات الحالية و المستقبلية لمكونات الهوية المعمارية و العمر انية. • مراقبة مؤشرات تحقق الهوية العمرانية والمعمارية و التصميم البئئي

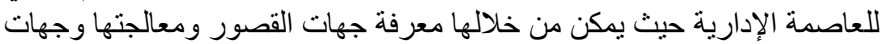
التمييز وتقويتها. 2. يجب ان تقوم المخططات المستقبلية للمدن الجديدة على أسس معمارية

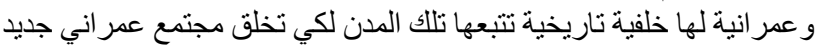

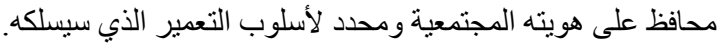

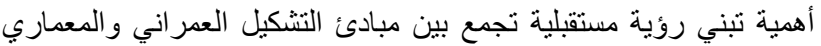

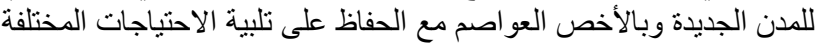

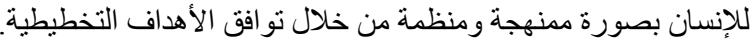

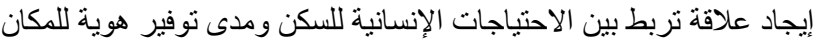

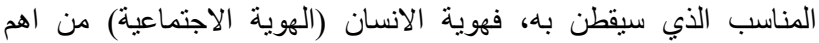

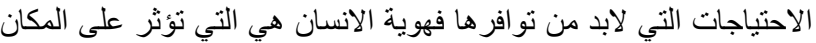

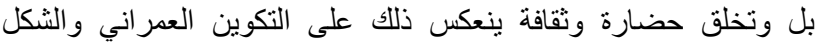

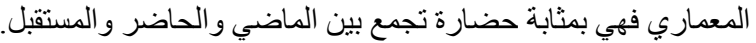
تفعيل دور المرصد الحضري في مر اقبة ورصد العمر ان الجديد ومر القية اقبة كيفية تنفيذ تلك المدن وتحقيق الهوية سواء المعمارية او العمر انية.

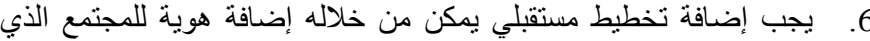

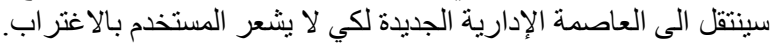

\section{XI}

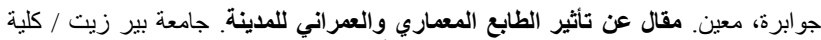
الهندسة والتكنولوجيا _قسم الهندسة ال معمارية 21 أيار 2019 